\title{
Voting For a Cartel as a Sign of Cooperativeness
}

\author{
Joris Gillet $^{1}$ - Middlesex University \\ October 2017
}

\begin{abstract}
:
This paper tests the hypothesis that a (partial) reason why cartels - costly non-binding price agreements - lead to higher prices in Bertrand Pricing Game-experiments could be because participants who form these kinds of agreements are more cooperative and pick higher numbers in general. To test this hypothesis we run an experiment where participants play two consecutive Bertrand oligopoly games: first a standard version without the opportunity to make price agreements; followed by a version where participants can vote, by majority, on whether to have a costly nonbinding agreement to pick the highest number. We find no statistically significant difference between the numbers picked in the first game by participants who vote for and against an agreement in the second game. We do confirm that having a price agreement leads to higher numbers being picked on average. Additionally we find that participants who vote for or against the price-agreement behave differently in response to the existence of the price agreement. In particular, participants who vote for a price agreement react more positively to the price agreement. The difference in numbers picked in the second game between situations with and without a price agreement is larger for participants who voted in favour of the agreement. Voters who voted for the price agreement are more cooperative than voters who voted against but only in situations where there is a price agreement.
\end{abstract}

Keywords: Bertrand Pricing Game, oligopoly, experimental economics.

JEL Codes: C91, D02, D43, L13.

\footnotetext{
${ }^{1}$ Joris Gillet, Middlesex University, Business School, Department of Economics, The Burroughs, NW4 4BT, London, United Kingdom, j.gillet@mdx.ac.uk. Conflicts of interest: none.
} 


\section{Introduction}

Non-binding price agreements lead to higher prices in experiments with Bertrand Pricing games (Apesteguia, Dufwenberg and Selten (2007), Gillet, Schram, Sonnemans (2011)). This paper tests the hypothesis that a (partial) reason why this happens, may be that the type of players who form these agreements are more cooperative and pick higher prices in general.

The Bertrand Pricing Game is a simple model of oligopoly competition in a market with homogenous goods. In an experimental setting (Dufwenberg and Gneezy (2000)) it usually works as follows: a number of participants simultaneously pick a number (here between 0 and 50) and the winner is the participant picking the lowest number. The earnings of the winners are equal to the number picked. The other participants earn nothing. If more than one participant picks the lowest number the earnings are shared equally between the winners. The game is an example of a social dilemma. The socially optimal outcome is where all players pick the highest possible price and share earnings but every individual player has an incentive to undercut their competitors and pick a lower price. The (one shot) Nash equilibrium is the situation where everyone picks the lowest number.

Previous experiments - see for instance also Hinloopen \& Soetevent (2009), Chowdhury \& Crede (2017), Chowdhury \& Wandschneider (2017) - show that costly non-binding agreements to pick the highest number lead to higher numbers being picked on average. One possible explanation for this finding could be that the kind of people who (want to) form a price-agreement are more cooperative than others and more likely to pick higher numbers in general. As far as I know these hypothesis has not been tested before.

The idea behind the hypothesis is straightforward. If we interpret making a (non-binding) agreement as a cooperative act it is not farfetched to expect that the willingness to make such an agreement is correlated with other measures of cooperativeness.

There are a number of earlier studies that look at why promises work. Ismayiov \& Potters (2015) use the trust game and find that promises are kept even when they are not received, suggesting that promises not just work because of feelings of social obligation but also because of a preference for internal consistency. Ellingsen and Johannesson (2004) also provide experimental and theoretical evidence for the role of consistency preference in an experiment with the hold-up problem. The goal of the current paper is not to replace any existing theories but to investigate the role of an additional factor. One aspect that most of the previous literature on the topic seems to have in common is that they treat promises as exogenous events. They investigate why promises are being kept and largely overlook the question why promises are made. Another difference is that this paper is concerned with multilateral promises - a group of people who make an agreement to each other to follow a certain 
action - and not with unilateral promises - one person making a promise to do something to someone else - like most of the existing literature.

To test our hypothesis we run an experiment where participants play two Bertrand oligopoly games in a row. First a standard version, without the opportunity to make price-agreements. This is followed by a version where participants can vote, by majority, on whether to have a (costly) non-binding agreement to pick the highest number.

We find no significant evidence that participants who vote for an agreement in the second game picked higher numbers in the first game. We do confirm the finding that having a price agreement leads to higher numbers being picked and also find that participants who voted for or against the price agreement behave differently in response to the existence of the price-agreement. Both For- and Against-voters pick higher numbers in situations with a price agreement but participants who voted for a price-agreement react more strongly to the existence of the price agreement.

\section{Methods}

The Bertrand Pricing Game used in the experiment worked as follows: there were three participants who each, simultaneously, picked a number between 0 and 50. The winner of the game is the participant who picked the lowest number and their earnings, in experimental points, were equal to the number that they picked. The other participants earned nothing. If two or more participants picked the same lowest number, the earnings were shared equally.

Participants played two consecutive Bertrand Pricing games. The first game was the basic game as described above. After choosing their number for the game, participants were also asked their expectation about the numbers being picked by the other participants in their game by guessing the average number being picked by the other two players. This question was incentivized by giving a correct - or almost correct, a difference of plus or minus 5 was close enough - answer a bonus payment. Participants did not receive feedback on the outcome of the first game at this point in the experiment.

After the first game participants were told they were going to play one more, final, game, with a different set of players than the first game. The rules of the game were going to be the same but now, before making their decision what number to pick, participants would have the opportunity to make an agreement with their co-players to pick the highest number. The group decision was by majority. When 2 or more of the group members voted for the agreement, the agreement was to be in effect. The agreement was non-binding; group members could still pick any number they wanted. There was a cost associated with the agreement. If the group formed an agreement there was a $20 \%$ chance that 
the results of the subsequent decision wouldn't count. In that case, nobody in the group would earn any points. Participants in the second game made three decisions: whether they voted for or against the agreement and, applying the strategy method, a price for a situation where the group decided for an agreement and a price for a situation without an agreement.

The experiment was run on Amazon Mechanical Turk. Because running interactive group experiments online is rather complicated (Arechar et al., 2017) - coordinating all participants to be, and stay, online at the same time etc. - we used post-hoc group formation. Participants made their decisions separately and in their own time. Only afterwards, once all participants had made their decisions and the data was collected, we combined the participants into groups and played out their interactions, and calculate their earnings, according to the decisions. Only after this process had happened we could tell, and pay, participants their earnings.

After reading the instructions to the first game, participants had to answer two comprehension questions to show that they had understood the game. Participants received a participation fee of $\$ 1.00$ and each point they earned was worth an additional $\$ 0.03$. The bonus payment for guessing the average number picked by the other members of their group correctly was $\$ 0.25$.

\section{Results}

In total 378 participants took part in two sessions, in August 2015 and March 2016. The experiment took not more than a couple of minutes to complete. Average earnings, including the participation fee, were $\$ 1.55$. In the following analysis we will only look at the decisions made by the 362 participants who answered both comprehension questions correctly. Of these 362 participants 152 were female and 209 were male (1 participant didn't answer this question). The average age was 33.99.

Of these 362 participants 183 voted for a price agreement and 179 voted against. When we look at the numbers they picked in the first, basic Bertrand game we see that the For-voters picked on average $21.69(\mathrm{sd}=11.07)$ and the Against-voters $19.67(\mathrm{sd}=10.62)$. The difference is not statistically significant $(\mathrm{p}=0.1416)^{2}$.

Figure 1 shows the cumulative distribution of numbers picked in the first game by the two types of voters. A Kolmogorov-Smirnov test cannot reject the hypothesis that the two distributions are the same $(\mathrm{p}=0.57)$.

\footnotetext{
${ }^{2}$ All statistical comparisons between two averages in this paper are based on two-tailed Mann-Whitney tests.
} 


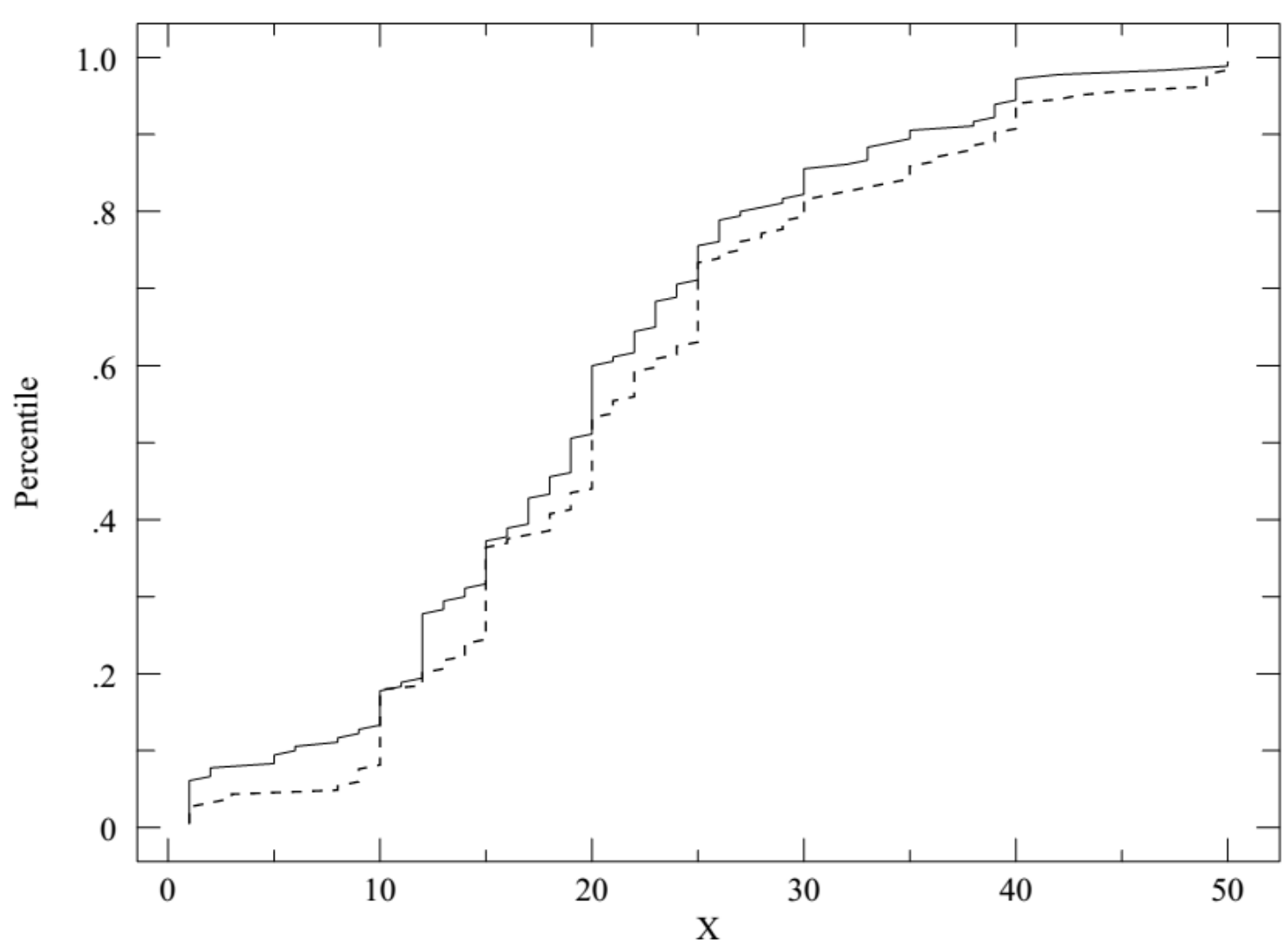

Figure 1: distribution of numbers picked by For-voters (continuous line) and Against-voters (dashed)

Expectations about what number was picked, on average, by the other members of the group were higher than the number the participants picked themselves: $25.62(\mathrm{SD}=10.75)$ vs. $20.70(10.88)$. This difference is statistically significant $(\mathrm{p}<0.0001)$. There is a high correlation between expectations and actual number picked $\left(\mathrm{R}^{2}=0.617, \mathrm{p}<0.0001\right)$. So, when we look at the difference in expectations between For- and Against-voters we see very similar results as for the actual choices: average expectations are $26.61(\mathrm{sd}=11.95)$ vs. $24.60(\mathrm{sd}=10.41)$ respectively. This difference is not significant $(\mathrm{p}=0.12)$.

There is also no difference between For- and Against-voters with regards to age. The average age of For-voters was $33.83(\mathrm{sd}=9.18)$ and of Against-voters $34.16(\mathrm{sd}=9.58)(\mathrm{p}=0.93)$. Nor is there a significant effect of gender. Women voted For and Against 70 to 82 and men voted 112 to 97 (p = 0.16 in a Chi-square test).

Even though it is non-binding the agreement leads to significantly higher numbers being picked. In the second game, when asked to pick a number for situations with an agreement participants pick on average $40.91(\mathrm{sd}=12.92)$ For situations without an agreement they pick on average $22.97(\mathrm{sd}=$ 11.42). This difference is significant, $\mathrm{p}<0.001$.

But when we distinguish between participants who voted For or Against the agreement we see that this effect is different. For situations without an agreement there is no significant difference between 
For- and Against-voters: $23.59(\mathrm{sd}=11.372)$ vs. $22.34(\mathrm{sd}=11.464), \mathrm{p}=0.35$. But for situations with an agreement For-voters pick on average a significantly higher number than Against-voters: 45.25 $(\mathrm{sd}=9.051)$ vs. 36.47 (14.693), $\mathrm{p}<0.001$. Figure 2 summarizes these findings.

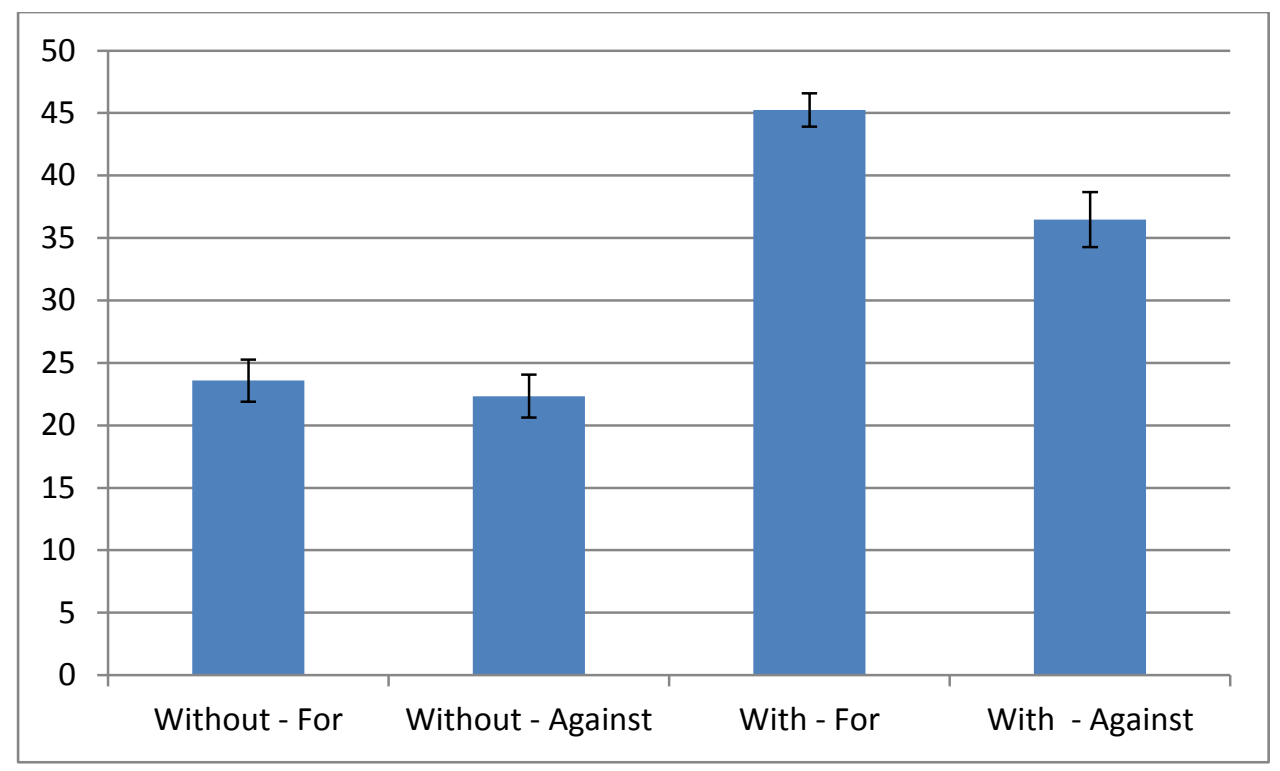

Figure 2: average number picked in situations with or without an agreement for participants who voted for or against the agreement (with $95 \%$ confidence bars).

\section{Conclusion}

The experiment described in this paper fails to find evidence for the hypothesis that (costly) nonbinding agreements lead to higher prices being picked in a Bertrand Pricing Game is because agreements are made by people who are more cooperative to begin with. Participants who voted for the price agreement in the second game do not pick significantly higher numbers in the first game than people who voted against.

We do find that For- and Against-voters react differently to the existence of an agreement. Both Forand Against-voters pick higher numbers in situations with an agreement but this increase is larger for those who voted for the agreement. One way of interpreting these findings is that there seems to be no difference in general, unconditional cooperativeness between For- and Against voters but that conditional on there being an agreement For-voters are more cooperative. 


\section{Literature}

Apesteguia, J., Dufwenberg, M., and Selten, R. (2007), Blowing the whistle, Economic Theory, 31 (1), 143-166

Arechar, A.A., Gächter, S., and Molleman, L. (2017), Conducting Interactive Experiments Online, Experimental Economics, 1-33

Chowdhury, S.M., and Crede, C.J. (2015), Post-Cartel Tacit Collusion: Determinants, Consequences, and Prevention, working paper

Chowdhury, S.M., and Wandschneider, F. (2017), Anti-trust and the 'Beckerian Proposition': the Effects of Investigation and Fines on Cartels, Handbook of Behavioral Industrial Organization, Forthcoming

Dufwenberg, M., and Gneezy, U. (2000), Price Competition and Market Concentration: an Experimental Study, International Journal of Industrial Organization, 18, 7-22

Ellingsom, T., and Johannesson, M. (2004), Promises, Threats and Fairness, The Economic Journal, 114 (april), 397-420

Gillet, J., Schram, A., and Sonnemans, J. (2011), Cartel formation and pricing: The effect of managerial decision-making rules, International Journal of Industrial Organization, 29 (1), 126-133

Hinloopen, J., and Soetevent, A.R. (2008), Laboratory evidence on the effectiveness of corporate leniency programs, Rand Journal of Economics, 39(2), 607-616

Ismayilov, H., and Potters, J. (2016), Why do promises affect trustworthiness, or do they?, 19 (2) Experimental Economics 